\title{
Cell-autonomous role of Presenilin in age- dependent survival of cortical interneurons
}

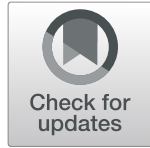

Jongkyun Kang ${ }^{1}$ and Jie Shen ${ }^{1,2^{*}}$

\begin{abstract}
Background: Mutations in the PSEN1 and PSEN2 genes are the major cause of familial Alzheimer's disease. Previous studies demonstrated that Presenilin (PS), the catalytic subunit of $y$-secretase, is required for survival of excitatory neurons in the cerebral cortex during aging. However, the role of PS in inhibitory interneurons had not been explored.

Methods: To determine PS function in GABAergic neurons, we generated inhibitory neuron-specific PS conditional double knockout (IN-PS CDKO) mice, in which PS is selectively inactivated by Cre recombinase expressed under the control of the endogenous GAD2 promoter. We then performed behavioral, biochemical, and histological analyses to evaluate the consequences of selective PS inactivation in inhibitory neurons.
\end{abstract}

Results: IN-PS CDKO mice exhibit earlier mortality and lower body weight despite normal food intake and basal activity. Western analysis of protein lysates from various brain sub-regions of IN-PS CDKO mice showed significant

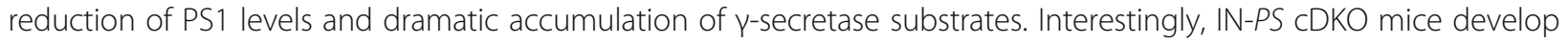
age-dependent loss of GABAergic neurons, as shown by normal number of GAD67-immunoreactive interneurons in the cerebral cortex at 2-3 months of age but reduced number of cortical interneurons at 9 months. Moreover, agedependent reduction of Parvalbumin- and Somatostatin-immunoreactive interneurons is more pronounced in the neocortex and hippocampus of IN-PS cDKO mice. Consistent with these findings, the number of apoptotic cells is elevated in the cerebral cortex of IN-PS CDKO mice, and the enhanced apoptosis is due to dramatic increases of apoptotic interneurons, whereas the number of apoptotic excitatory neurons is unaffected. Furthermore, progressive loss of interneurons in the cerebral cortex of IN-PS CDKO mice is accompanied with astrogliosis and microgliosis.

Conclusion: Our results together support a cell-autonomous role of PS in the survival of cortical interneurons during aging. Together with earlier studies, these findings demonstrate a universal, essential requirement of PS in the survival of both excitatory and inhibitory neurons during aging.

Keywords: Alzheimer's disease, Conditional knockout mouse, Cerebral cortex, GABAergic, Interneurons, Excitatory neurons, Apoptosis, Neuronal death, Astrogliosis, Microgliosis

\footnotetext{
* Correspondence: jshen@bwh.harvard.edu

'Department of Neurology, Brigham and Women's Hospital, Boston, MA 02115, USA

${ }^{2}$ Program in Neuroscience, Harvard Medical School, Boston, MA 02115, USA
}

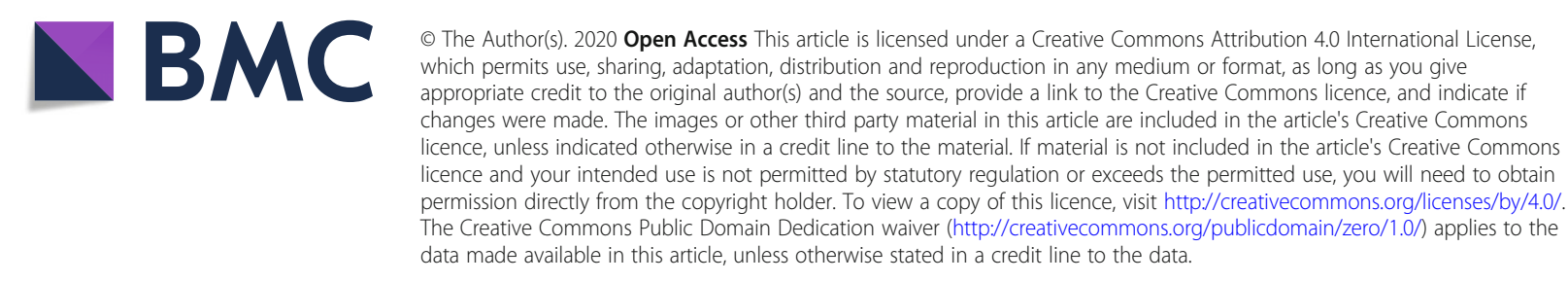




\section{Background}

Alzheimer's disease (AD) is the most common neurodegenerative disorder afflicting $\sim 50$ million people worldwide. Dominantly inherited mutations in the Presenilin genes (PSEN1 and PSEN2) account for $90 \%$ of mutations identified in familial Alzheimer's disease (FAD), highlighting their importance in the pathogenesis [1]. Presenilin-1 (PS1) and PS2 are highly expressed in neurons throughout development and in adulthood [2-4], and PS is the catalytic subunit of the $\gamma$-secretase complex [5]. Genetic studies in mice showed that during development PS regulates neurogenesis and cell-fate decisions in the brain [6-8] as well as tumorigenesis in the skin [9]. In the adult cerebral cortex, PS $/ \gamma$-secretase plays an essential role in excitatory neurons; selective inactivation of PS or another essential component of the $\gamma$-secretase complex, Nicastrin, in excitatory neurons of postnatal forebrain results in memory impairment, deficits in synaptic plasticity, and age-dependent neurodegeneration including gliosis [10-19].

The cerebral cortex is composed of glutamatergic excitatory projection neurons and local GABAergic inhibitory interneurons, and inhibitory neurons regulate the overall balance of excitatory and inhibitory neuronal activities via inhibitory neurotransmitter, $\gamma$-aminobutyric acid (GABA). Interneurons represent $10-20 \%$ of the neuronal populations in the cerebral cortex, and they are a highly heterogenous group of neurons with distinct morphological, electrophysiological, and neurochemical characteristics [20-22]. The largest group of cortical interneurons is calcium binding protein Parvalbumin (PV)-expressing neurons, which represent $\sim 40 \%$ total interneurons. PV-expressing interneurons provide somatic inhibition to pyramidal neurons and display fast-spiking activity. A second class of interneurons expresses the neuropeptide somatostatin (SST), and it represents $\sim 30 \%$ of total interneurons in the cortex. SST-expressing interneurons provide distal inhibition and display more gradual, delayed response to stimulation. A third group of cortical interneurons generally express the serotonin receptor 5HT3aR, but this interneuron group is very diverse with varying morphologies and releasing neuromodulators [23, 24]. It has been reported that the number of inhibitory neurons, especially PV- or SST-expressing interneurons, is reduced in various sub-regions of postmortem AD brains, such as the entorhinal cortex and the hippocampus [25-31]. In addition, dysfunction of GABAergic neurotransmission and imbalance of the neural network have emerged as one of the potential mechanisms of cognitive dysfunction in $\mathrm{AD}[32,33]$. Despite the importance of inhibitory neurons in AD pathogenesis, the role of PS in inhibitory neurons had not been studied.
To address this important question, we generated inhibitory neuron-specific PS conditional double knockout mice (IN-PS cDKO), in which PS is selectively inactivated in GABAergic inhibitory neurons using the GAD2IRES-Cre driver [34]. IN-PS cDKO mice are fertile but exhibit earlier mortality. Importantly, IN-PS $\mathrm{cDKO}$ mice exhibit age-dependent loss of interneurons and increases of apoptosis as well as astrogliosis and microgliosis in the cerebral cortex, demonstrating an essential protective role of PS in the survival of cortical interneurons during aging.

\section{Methods}

\section{Generation of inhibitory neuron-specific PS CDKO mice}

All mice were housed in humidity- and temperaturecontrolled rooms maintained on a 12:12 h light: dark cycle, and were given standard rodent chow and water. To generate inhibitory neuron-specific PS cDKO (IN-PS cDKO) mice, we first crossed homozygous floxed PS1 (fPS1/fPS1); PS2-/- mice [13] with GAD2-IRES-Cre knockin (KI) mice (The Jackson Laboratory, 010802, RRID: IMSR_JAX:010802) [34] to obtain fPS1/+; PS2+/ -; GAD2-IRES-Cre/+ mice, which were then bred with fPS1/fPS1; PS2-/- mice to generate fPS1/fPS1; PS2-/-; GAD2-IRES-Cre/+ (IN-PS cDKO) mice. IN-PS cDKO and littermate control mice used in the study were obtained from breeding fPS1/fPS1; PS2-/- mice together with fPS1/fPS1; PS2-/-; GAD2-IRES-Cre/+ or fPS1/+; PS2-I-; GAD2-IRES-Cre/+ mice. Both IN-PS cDKO male and female mice are viable and fertile with normal size litters $(7.34 \pm 0.23$ mice per litter, total 279 pups from 38 litters). Genotyping was performed at postnatal days 10-12, and the progeny of intercrosses of IN-PS $\mathrm{cDKO}$ and control mice were found at the expected Mendelian ratio $\left(\mathrm{F}_{1}=1.294, p=0.26\right.$, Chi-square; Control: $N=130$, cDKO: $N=149$ ).

Both male and female mice were used in each experiment. IN-PS cDKO and littermate control mice were maintained in the C57BL/6 J 129 hybrid genetic background. The experimenter of all behavioral and quantitative histological analyses was blind to the genotype of the mice.

All procedures were approved by the IACUC committees of Harvard Medical School and Brigham and Women's Hospital, and conform to the USDA Animal Welfare Act, PHS Policy on Humane Care and Use of Laboratory Animals, the "ILAR Guide for the Care and Use of Laboratory Animals" and other applicable laws and regulations.

\section{PCR genotyping}

Tail genomic DNA was extracted at postnatal days 1012. The primers used in the PCR to differentiate the wild-type, floxed or deleted PS1 allele are P140 (5'- 
TCAACTCCTCCAGAGTCAGG, forward primer in PS1 intron 1), P158 (5'-TGCCCCCTCTCCATTTTCTC, reverse primer in PS1 intron 1), and P139 (5'-GGTTTC CCTCCATCTTGGTTG, reverse primer in PS1 intron 3 ). The $216 \mathrm{bp}$ PCR product (from P140-P158) represents the wild-type PS1 allele, whereas the $262 \mathrm{bp}$ fragment represents the floxed PS1 allele. The $372 \mathrm{bp} \mathrm{PCR}$ product (from P140-P139) represents the deleted PS1 allele. The primers used in the PCR to differentiate the wild-type or deleted PS2 allele are P162 (5'-CATCTA CACGCCCTTCACGG, forward primer in PS2 exon 5), P163 (5'-CACACAGAGAGGCTCAGGATC, reverse primer in PS2 intron 5), and P164 (5'-AAGGGCCAGC TCATTCCTCC, forward primer in the $P G K$ sequences of the PGK-Neo selection cassette). The $581 \mathrm{bp} \mathrm{PCR}$ product (from P162-P163) represents the wild-type PS2 allele, whereas the $326 \mathrm{bp}$ PCR product (from P163P164) represents the deleted PS2 allele. The primers used in the PCR to differentiate the wild-type or the GAD2-IRES-Cre KI allele are JKM028 (5'-CTTCTTCC GCATGGTCATCT, forward primer in the coding sequences of GAD2 exon 16), JKM029 (5'-CACCCCAC TGGTTTTGATTT, reverse primer in the 3' UTR of GAD2 exon 16), and JKM030 (5'-AAAGCAATAG CATCACAAATTTCA, reverse primer in the SV40 polyA signal sequences of IRES-Cre, inserted immediately following the stop codon of the GAD2 gene in exon 16). The $250 \mathrm{bp} \mathrm{PCR} \mathrm{product} \mathrm{(from} \mathrm{JKM028-JKM029)}$ represents the wild-type GAD2 allele, whereas the 352 bp fragment (from JKM028-JKM030) represents the Cre KI allele.

\section{Daily food intake analysis}

IN-PS cDKO mice $(N=8,5$ male and 3 female) and littermate controls $(N=8,5$ male and 3 female) at 2 months of age were separated into single-housed cages. Food intake of individual mice was measured daily for 7 days, and an average daily food intake per mouse was calculated by averaging the quantity of food consumed over 7 days.

\section{Open field test}

IN-PS cDKO mice ( $N=11,9$ male and 2 female) and littermate controls $(N=10,5$ male and 5 female) at 2 months of age were used for the analysis. Individual mice were handled daily for 5 days before testing. During the test, individual mice were placed in $42 \times 42 \mathrm{~cm}$ acrylic animal cages for 15 min during which their horizontal and vertical movements were monitored by three arrays of 16 infrared light beam sensors (AccuScan Instruments) connected to a computer that recorded their position every millisecond. AccuScan VersaMax software was then used to calculate, in both the horizontal plane and along the vertical axis, the total number of movements, distance traveled, time spent moving, and the total number of infrared beam breaks for each mouse.

\section{Western analysis}

Each brain sub-region was dissected from the harvested brain. Fresh tissues were homogenized in an ice-cold stringent RIPA buffer [50 mM Tris-Cl (pH 7.6), $150 \mathrm{mM}$ $\mathrm{NaCl}, 0.5 \mathrm{mM}$ EDTA, 1\% NP40, 0.5\% sodium deoxycholate, $0.1 \%$ SDS, $1 \mathrm{mM}$ PMSF supplement with protease inhibitor cocktail and phosphatase inhibitor cocktail (Sigma)], followed by sonication. Homogenates were centrifuged at $14,000 \mathrm{rpm}$ for $20 \mathrm{~min}$ at $4{ }^{\circ} \mathrm{C}$ to separate supernatants (RIPA buffer-soluble fraction). Equal amounts (10-40 $\mu \mathrm{g}$ per lane) of total proteins from each preparation were loaded and separated on NuPAGE gels (Invitrogen), and transferred to nitrocellulose membranes. The membranes were blocked in $5 \%$ skim milk/ TBS for $1 \mathrm{~h}$, and incubated at $4{ }^{\circ} \mathrm{C}$ overnight with specific primary antibodies. The primary antibodies used were mouse anit-PS1 (MAB5232, MilliporeSigma, 1/ 1000, RRID: AB_95175), rabbit anti-APP-Y188 (ab32136, Abcam, 1/2000, RRID: AB_2289606), rabbit anti-MAP 2 (\#4542, Cell Signaling, 1/1000, RRID: AB_776174), rabbit anti-SYP (\#5431, Cell Signaling, 1/1000, RRID: AB_ 10698743), rabbit anti-SNAP25 (ab108990, abcam, 1/ 2000, RRID: AB_10888111), rabbit anti-PSD95 (\#2507, Cell Signaling, 1/1000, RRID: AB_1264242), mouse antiGFAP (G6171, 1/2000, Sigma-Aldrich, RRID: AB 1840893), or mouse anti- $\beta$-actin (\#3700, Cell Signaling, 1/4000, RRID: AB_2242334). Membranes were then incubated with secondary antibodies, which was either goat anti-rabbit IRdye680 (926-68,071, LI-COR Bioscience, 1/20000, RRID: AB_10956166), goat anti-mouse IRdye680 (926-68,072, LI-COR Bioscience, 1/20000, RRID: AB_10953628), or goat anti-mouse IRdye800 (926-32,210, LI-COR Bioscience, 1/20000, RRID: AB 621842). Signals were quantified using the Odyssey Infrared Imaging System (LI-COR Biosciences).

\section{Histological analysis}

Mice were anesthetized with ketamine $(100 \mathrm{mg} / \mathrm{kg})+$ xylazine $(10 \mathrm{mg} / \mathrm{kg})+$ acepromazine $\quad(3 \mathrm{mg} / \mathrm{kg})$, and transcardially perfused with phosphate-buffered saline solution (PBS, pH 7.4) containing $0.25 \mathrm{~g} / \mathrm{L}$ heparin (Sigma) and $5 \mathrm{~g} / \mathrm{L}$ procaine (Sigma). Brains were postfixed in $4 \%$ formaldehyde in PBS (Electron Microscopy Sciences) at $4{ }^{\circ} \mathrm{C}$ overnight and then processed for paraffin embedding following standard procedures. Serial sagittal sections $(10 \mu \mathrm{m})$ were obtained using Leica RM2235. For Nissl staining, paraffin sagittal sections were deparaffinized, dehydrated, and stained with $0.5 \%$ cresyl violet (Sigma-Aldrich). Immunohistochemical analysis was performed as previously described [35]. 
Briefly, paraffin sagittal sections were deparaffinized, alcohol-dehydrated, then subjected to permeabilization with a solution containing $0.1 \%$ Triton X-100, $0.1 \%$ sodium citrate in PBS, except those for cleaved-caspase3 immunostaining, which were performed antigen retrieval by microwaving for $10 \mathrm{~min}$ in $10 \mathrm{mM}$ sodium citrate buffer, pH 6.0. Endogenous peroxidase activity was quenched by incubating in $0.3 \% \mathrm{H}_{2} \mathrm{O}_{2}$ in methanol. Sections were then blocked with a PBS solution containing $5 \%$ normal goat serum (Vector Laboratories) for $1 \mathrm{~h}$ at room temperature. After blocking, sections were incubated with primary antibodies overnight at $4{ }^{\circ} \mathrm{C}$. The primary antibodies used were mouse anti-GAD67 (MAB5406, MilliporeSigma, 1/1000, RRID: AB 2278725), mouse anti-PV (P3088, MilliporeSigma, 1/ 1000, RRID: AB_744329), rat anti-SST (MAB354, MilliporeSigma, 1/300, RRID: AB_2255365), rabbit anticleaved caspases-3 (\#9661, Cell Signaling Technology, 1/ 150, RRID: AB_2341188), mouse anti-GFAP (G6171, Sigma-Aldrich, 1/500, RRID: AB_1840893), or rabbit anti-Iba1 (\#019-19,741, Wako, 1/300, RRID: AB 839504). Sections were then incubated for $1 \mathrm{~h}$ with biotinylated secondary antibodies at room temperature, followed by $1 \mathrm{~h}$ incubation with Vectastain Elite $A B C$ reagent, and then developed using chromogenic DAB substrate (Vector Laboratories, RRID: AB_2336827).

For the TUNEL assay, deparaffinized and rehydrated brain sections were subjected to permeabilization with a solution containing $0.1 \%$ Triton X-100, $0.1 \%$ sodium citrate in PBS for $8 \mathrm{~min}$. Sections were then blocked with a solution containing 5\% normal goat serum (Vector Laboratories) for $1 \mathrm{~h}$ at room temperature, followed by the protocol of the manufacturer of the In Situ Cell Death Detection kit (Roche). The slides were then washed using PBS three times. Images were captured and analyzed using an Olympus IX51 fluorescent microscope.

For the immunofluorescence staining, deparaffinized and rehydrated brain sections were subjected to permeabilization with a solution containing $0.1 \%$ Triton $\mathrm{X}-100,0.1 \%$ sodium citrate in PBS, and antigen retrieval was performed by microwaving for $10 \mathrm{~min}$ in $10 \mathrm{mM}$ sodium citrate buffer, $\mathrm{pH} 6.0$. Sections were then blocked with a solution containing 5\% normal goat serum (Vector Laboratories) for $1 \mathrm{~h}$. After blocking, sections were incubated with primary antibodies overnight at $4{ }^{\circ} \mathrm{C}$. The primary antibodies used were mouse antiGAD67 (MAB5406, MilliporeSigma, 1/500, RRID: AB 2278725), mouse anti-CaMKII (MA1-048, Thermo Fisher Scientific, 1/200, RRID: AB_325403), or rabbit anti-cleaved caspases-3 (\#9661, Cell Signaling Technology, 1/150, RRID: AB_2341188). Sections were then incubated for $1 \mathrm{~h}$ with fluorophore conjugated secondary antibodies, Alexa Fluor 488 goat anti-rabbit IgG (A11034, Thermo Fisher Scientific, 1/250, RRID: AB_
2576217) and Alexa Fluor 555 goat anti-mouse IgG (A21424, Thermo Fisher Scientific, 1/250, RRID: AB_ $141780)$ at room temperature. Fluorescence images were taken and analyzed by FV1000 confocal microscope system (Olympus).

\section{Stereological quantification}

Stereological quantification was performed as previously described using the BioQuant image analysis software that was connected to the Olympus BX51 microscope with a CCD camera [35]. Specifically, the volume of the neocortex or hippocampus was quantified using Nissl stained serial sections (every $40^{\text {th }}$ sagittal sections, spaced $0.4 \mathrm{~mm}$ apart; total $6-7$ sections per hemisphere). The entire area of the neocortex or hippocampus was analyzed, and the data were calculated to reflect the volume of both hemispheres $(N \geq 6$ mice per genotype per age group).

The number of GAD67-immunoreactive interneurons was quantified using GAD67 stained serial sections (every $40^{\text {th }}$ sagittal sections, spaced $0.4 \mathrm{~mm}$ apart; total 6-7 sections per hemisphere). An unbiased fractionator and optical dissector method [35] were used to count GAD67-immunoreactive cells in the neocortical area. Approximately forty optical dissectors of the $250 \times$ $250 \mu \mathrm{m}$ sampling box were used for the quantification. The number of neurons was counted with an indicator of immunopositive cells in the soma through the $20 \mathrm{X}$ objective lens from all the picked slides. In the hippocampus, the total number of GAD67-immunoreactive cells was calculated by multiplying 40 by the total number of immunopositive cells in the hippocampus of one hemisphere in all 6-7 sections. Finally, average number of neurons per hemisphere was calculated per genotype ( $N \geq 6$ mice per genotype per age group).

Similarly, the number of PV- or SST-immunoreactive inhibitory neurons was quantified using PV- or SSTstained serial sections (every $40^{\text {th }}$ sagittal sections, spaced $0.4 \mathrm{~mm}$ apart; total 6-7 sections per hemisphere). The total number of PV- or SST-immunoreactive cells in the neocortex or hippocampus was calculated by multiplying 40 with the total number of immunoreactive cells in each brain sub-region of one hemisphere in all 6-7 sections. Finally, average number of neurons per hemisphere was calculated per genotype ( $N \geq 6$ mice per genotype per age group).

The number of active caspase-3-immunoreactivity cells or TUNEL+ cells in the cerebral cortex was determined using serial sections (every $30^{\text {th }}$ sagittal sections, spaced $0.3 \mathrm{~mm}$ apart; 7-9 sections per hemisphere), and the number of positive cells was counted. The total number of active caspase-3-immunoreactivity or TUNEL+ cells in the cerebral cortex of the hemisphere was calculated by multiplying 30 with the total number 
of active caspase-3-immunopositive or TUNEL+ cells in each brain sub-region of one hemisphere in all 7-9 sections. Finally, average immunopositive cells or TUNEL+ cells per hemisphere was calculated per genotype $(N \geq 6$ mice per genotype per age group).

The quantification of apoptotic cells labeled with active caspase-3-immunoreactivity and GAD67- or CaMKII $\alpha$-immunoreactivity was performed using serial sections (every $30^{\text {th }}$ sagittal sections, spaced $0.3 \mathrm{~mm}$ apart; 5 sections per hemisphere). Single or double immunolabeled cells were counted across the entire cerebral cortex area under FV1000 confocal microscope system (Olympus), and the number of positive cells per section was averaged per genotype $(N \geq 7$ mice per genotype).

The GFAP-immunoreactive areas were analyzed using GFAP stained serial sections (every $40^{\text {th }}$ sagittal sections, spaced $0.4 \mathrm{~mm}$ apart; 6-7 sections per hemisphere). The GFAP-immunoreactive area and the total area of the neocortex or hippocampus, were measured under $4 \mathrm{X}$ objective, and the percentage of GFAP-immunoreactive area was calculated as GFAP+ area/total area. Finally, average GFAP+ area/total area \% per hemisphere was calculated per genotype $(N \geq 6$ mice per genotype per age group).

The Iba1-immuonreactive cells were analyzed using Iba1 stained serial sections (every $40^{\text {th }}$ sagittal sections, spaced $0.4 \mathrm{~mm}$ apart; 6-7 sections per hemisphere). The number of Iba1+ cells was counted using the unbiased fractionator and optical dissector methods and the BioQuant image analysis software. Optical dissectors of the $100 \times 100 \mu \mathrm{m}$ sampling box were used for the quantification in the neocortex, and $250 \times 250 \mu \mathrm{m}$ sampling box were used for the quantification in the hippocampus. The Iba1+ signal was calculated as the Iba1+ cell number/total area $(N \geq 7$ mice per genotype). Values are reported as mean \pm SEM. The coefficient of error from the stereological counting technique was $<0.10$.

\section{Experimental design and statistical analysis}

Data acquisition and quantification were performed in a genotype blind manner except for the molecular analysis. All statistical analysis was performed using Prism 8 (GraphPad software) or Excel (Microsoft). All data are presented as mean \pm SEM. The exact sample size, the number of mice or neurons, of each experiment is indicated in the figure or the legend.

Statistical analyses were conducted using two-tailed Student's $t$-test for the comparison of a given variable in two genotypes or two-way ANOVA followed by Bonferroni's post hoc comparisons for the comparison of more than two conditions. All statistical comparisons were performed on data from $\geq 6$ biologically independent samples and replicated on different experimental days.
Significance is shown as ${ }^{*} p<0.05,{ }^{* *} p<0.01,{ }^{* * *} p<0.001$, $* * * * 0<0.0001$, and not significantly different values are often not noted.

\section{Results}

Generation and molecular validation of IN-PS CDKO mice

To investigate the normal physiological role of PS in inhibitory interneurons, we generated IN-PS cDKO mice, in which PS inactivation is restricted to inhibitory interneurons by the GAD2-IRES-Cre driver [34], resulting in Cre-mediated deletion of PS1 exons 2-3 [10, 13, 36]. Similar to the generation of excitatory neuron-specific $P S$ cDKO (EX-PS cDKO) mice using an excitatory neuron specific driver, Camk2a-Cre [10, 13], mice homozygous for the floxed PS1 (fPS1) and PS2-null alleles (fPS1/fPS1; PS2-/-) were crossed with GAD2IRES-Cre KI mice to obtain $f P S 1 /+$; PS2+/-; GAD2IRES-Cre/+ mice, which were then bred with fPS1/fPS1; $P S 2-/-$ to generate IN-PS cDKO (fPS1/fPS1; PS2-/-; GAD2-IRES-Cre/+). IN-PS cDKO mice were further bred with fPS1/fPS1; PS2-/- mice to obtain IN-PS cDKO mice and littermate controls (fPS1/fPS1; PS2-/-) for phenotypic characterization. IN-PS cDKO mice were obtained at the expected Mendelian ratio at postnatal days $12-14$, indicating that they survive normally during the embryonic and early postnatal development.

Interestingly, IN-PS cDKO mice show early mortality; they start to die after 2 months of age, and few live beyond 11 months of age (Fig. 1a). While IN-PS cDKO mice exhibit normal body weight at 2 months of age, they show significantly lower body weight, relative to controls, at the ages of 3 and 9 months (Fig. 1b). However, the brain weight of IN-PS cDKO mice is normal relative to controls at all ages examined (e.g. at 9 months, Control: $492.2 \pm 10.8 \mathrm{mg}$, cDKO: $490.3 \pm 15.6$ mg, $p=0.92$, Student's $t$-test). To determine whether the lower body weight and the earlier mortality of IN-PS cDKO mice are due to poor feeding, we measured their daily food consumption, and found no difference between IN-PS cDKO mice and controls (Fig. 1c). We further evaluated IN-PS $\mathrm{cDKO}$ and control mice in the open field test, and found no genotypic difference in total movements $(p=0.43$, Student's $t$-test), stereotypy counts $(p=0.73)$, and time spent in the margin or the center $(p=0.06)$ of the open field arena (Fig. 1d).

It was previously shown that the GAD2-IRES-Cre KI allele drives Cre-mediated recombination in $>90 \%$ of GAD67-immunoreactive cortical interneurons [34]. We therefore anticipated that GAD2-IRES-Cre would similarly delete the floxed PS1 exons 2-3 in GABAergic interneurons of IN-PS cDKO mice. Due to the lack of specific PS1 antibodies that can be used for coimmunohistochemical analysis of PS1 and GAD67 in IN-PS cDKO brains, we performed Western analysis 


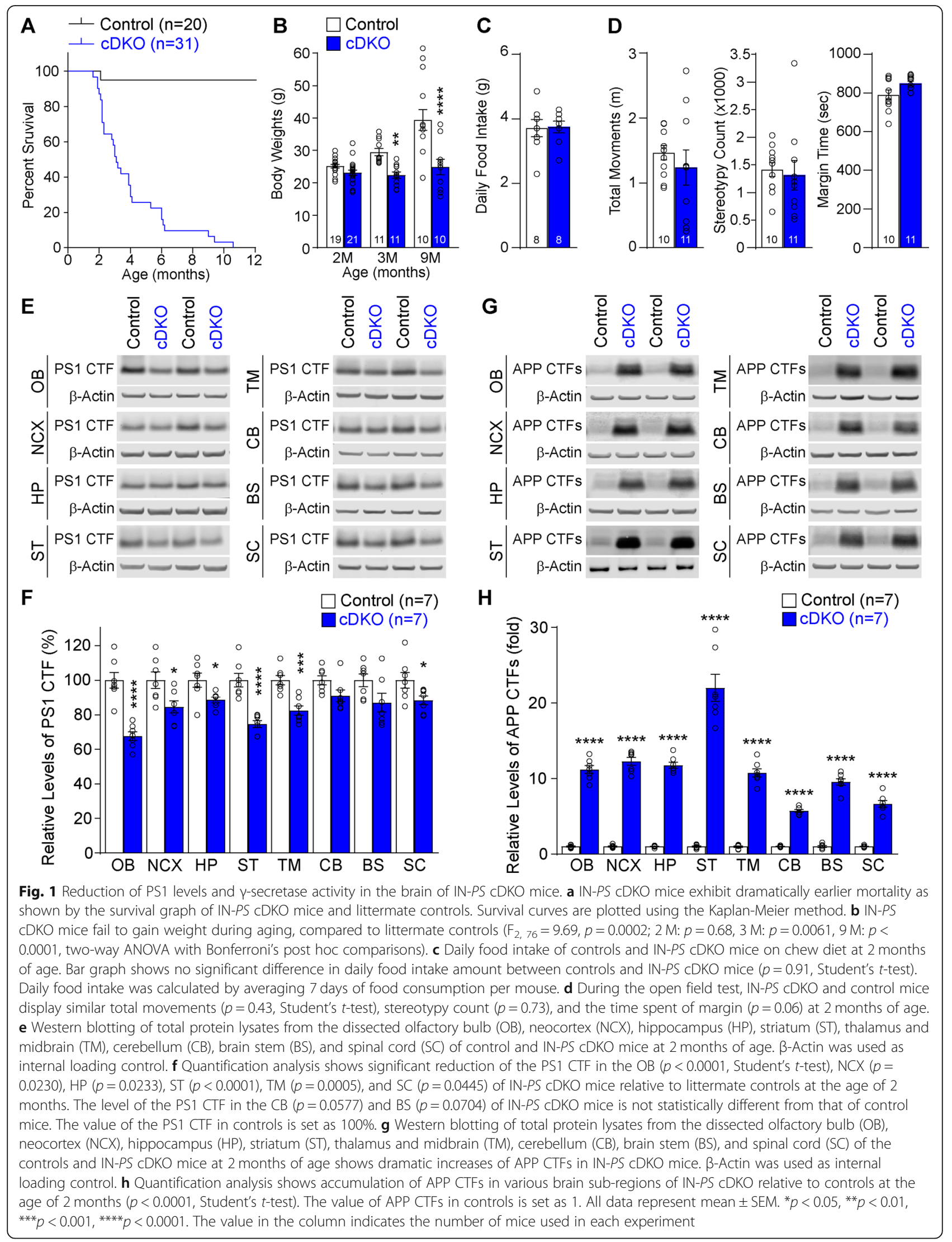


using protein lysates from dissected brain sub-regions from IN-PS cDKO mice and littermate controls at the age of 2 months to verify the reduction of PS1 expression in the IN-PS cDKO brain. We found that levels of the PS1 C-terminal fragment (CTF) are significantly decreased in the olfactory bulb $(p<0.0001$, Student's $t$ test), neocortex $(p=0.0230)$, hippocampus $(p=0.0233)$, striatum $(p<0.0001)$, thalamus/midbrain $(p=0.0005)$, and spinal cord $(p=0.0445)$, relative to littermate controls (Fig. 1e, f). The varying degree of partial reductions of the PS1 CTF is consistent with the varying percentage of GABAergic neurons present in the brain sub-regions, as lysates contain proteins not only from interneurons but also from excitatory neurons and glial populations, in which Cre is not expressed thus PS1 expression unaffected.

We previously reported that in the cerebral cortex of EX-PS cDKO mice, the CTFs of the amyloid precursor protein (APP), which are physiological substrates of $\gamma$ secretase, accumulate to very high levels (30-fold) relative to control mice at 2 months of age, due to the complete inactivation of $\mathrm{PS} / \gamma$-secretase in cortical excitatory neurons [10]. We therefore similarly measured levels of APP CTFs in various sub-regions of IN-PS cDKO brains at 2 months of age. Western analysis indeed showed dramatic accumulation of APP CTFs to varying degrees in all brain sub-regions examined with $\sim 12$-fold accumulation in the neocortex and hippocampus of IN-PS cDKO mice (Fig. 1g, h). These results are consistent with the lower percentage (10-20\%) of interneurons, relative to excitatory neurons, in the cerebral cortex. Due to the low levels of APP CTFs in the control brain and the very high levels of APP CTFs in the IN-PS cDKO brain, which makes accurate estimation more challenging, we performed serial dilutions $(1: 2,1: 3,1: 5$, $1: 10,1: 20,1: 30)$ of lysates from each of the brain subregions of IN-PS cDKO mice followed by Western blotting (Supplemental Figure 1). We found similar fold accumulation of APP CTFs in various brain sub-regions of IN-PS cDKO mice. These results confirmed inactivation of PS and loss of $\gamma$-secretase activity in IN-PS cDKO brains.

\section{Normal generation of cortical interneurons in IN-PS CDKO mice}

Cre recombinase expressed from the GAD2-IRES-Cre KI allele is under the control of the GAD2 promoter, which begins its expression approximately at embryonic day 10.5 [37]. We therefore performed histological analysis of IN-PS cDKO and control brains at 2 months of age to determine whether generation and specification of GABAergic neurons is affected in IN-PS cDKO mice. Since the cerebral cortex is the major brain sub-region affected by AD pathogenesis, we focused our phenotypic analysis on the neocortex and the hippocampus. Nissl staining revealed no gross abnormality in IN-PS $\mathrm{CDKO}$ brains (Fig. 2a). Stereological quantification showed similar volume of the neocortex (Control: $24.91 \pm 0.49$ $\mathrm{mm}^{3}$; cDKO: $25.73 \pm 0.81 \mathrm{~mm}^{3}, p=0.41$, Student's $t$-test) and the hippocampus (Control: $8.11 \pm 0.28 \mathrm{~mm}^{3}$; cDKO: $\left.7.89 \pm 0.20 \mathrm{~mm}^{3}, p=0.55\right)$ between IN-PS cDKO mice and littermate controls (Fig. 2b). Inhibitory interneurons labeled by GAD67 immunoreactivity appear normal in the neocortex and hippocampus of IN-PS cDKO brains (Fig. 2c). Stereological quantification showed similar number of GAD67-immunopositive inhibitory interneurons in the neocortex (Control: $2.87 \pm 0.08 \times 10^{5}$; $\mathrm{cDKO}$ : $2.97 \pm 0.11 \times 10^{5}, \quad p=0.45$, Student's $t$-test) and the hippocampus (Control: $3.37 \pm 0.10 \times 10^{4}$; cDKO: $3.59 \pm$ $\left.0.14 \times 10^{4}, p=0.23\right)$ between IN-PS cDKO mice and littermate controls (Fig. $2 \mathrm{~d}$ ). These results indicate that selective inactivation of PS in the IN-PS cDKO embryonic brain by GAD2-IRES-Cre does not affect the generation and specification of interneurons in the cerebral cortex.

\section{Age-dependent loss of cortical interneurons in IN-PS cDKO mice}

We further examined whether selective inactivation of PS in inhibitory interneuron affects their survival during aging. We performed histological analysis of IN-PS cDKO and control brains at the ages of 3 and 9 months. Nissl staining showed normal cortical morphology in IN-PS cDKO brains, and stereological quantification revealed unchanged volume of the neocortex and hippocampus in IN-PS cDKO mice at the age of 3 or 9 months (Fig. 3a, b). We also quantified the number of inhibitory interneurons in the cerebral cortex of IN-PS cDKO mice and littermate controls. Stereological quantification revealed that relative to control mice, the number of GAD67-immunoreactive interneurons is significantly reduced in the neocortex of IN-PS cDKO mice at 9 months (Control: $2.86 \pm 0.06 \times 10^{5}$, cDKO: $2.40 \pm$ $0.14 \times 10^{5}, p=0.0167$, two-way ANOVA with Bonferroni's post hoc comparisons) but not at 3 months (Fig. 3c). In the hippocampus, the number of GAD67immunopositive neurons is not significantly altered in IN-PS CDKO mice at 3 or 9 months of age (Fig. 3d).

We further examined two major sub-groups of inhibitory interneurons, Parvalbumin (PV)- or Somatostatin (SST)-expressing interneurons in the cerebral cortex of IN-PS CDKO mice. PV is a calcium binding protein, and is expressed in $\sim 40 \%$ of GABAergic interneurons in the cerebral cortex, whereas SST is a neuropeptide expressed in $\sim 30 \%$ of cortical interneurons [38-40]. To determine whether these sub-groups of interneurons are affected in IN-PS cDKO mice, we performed immunohistological analysis using antibodies specific for PV or 
A

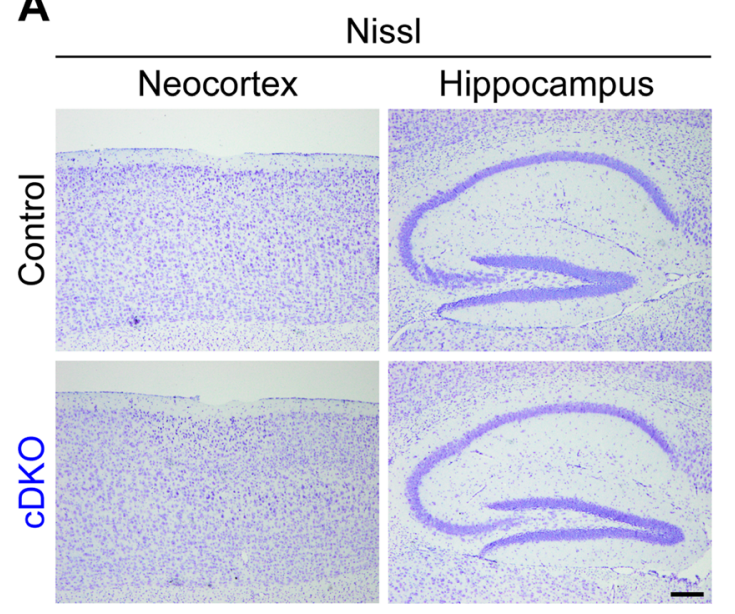

C

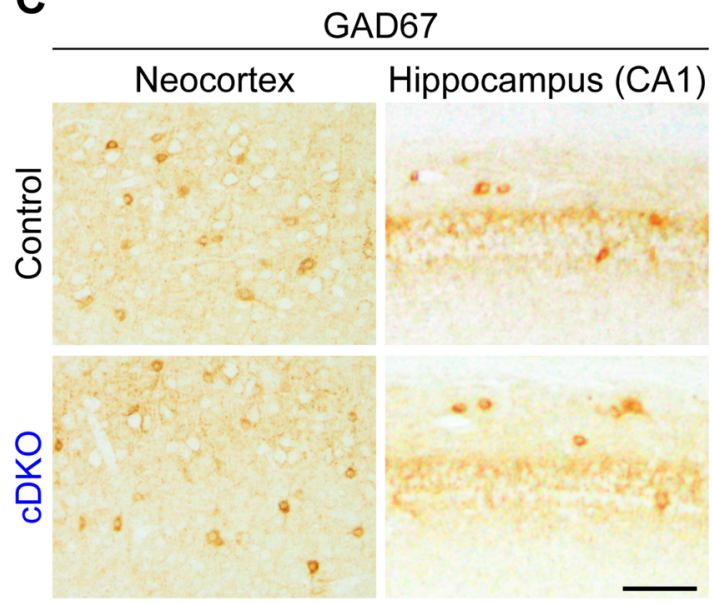

B

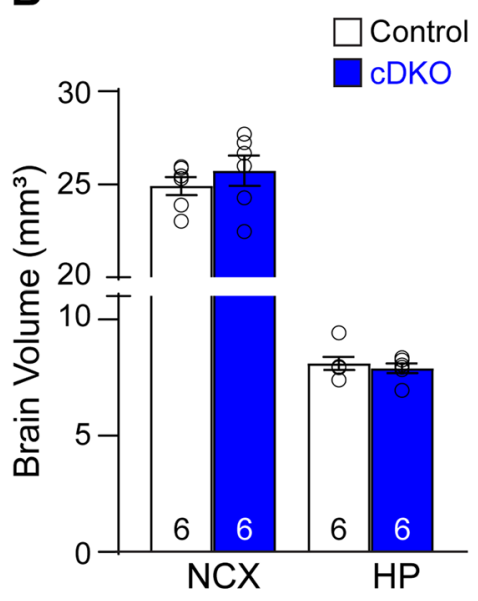

D

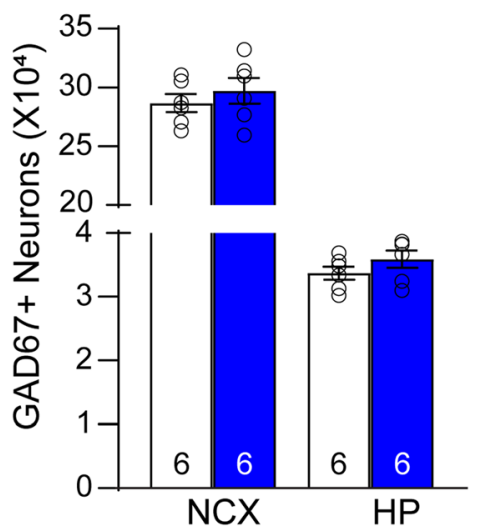

Fig. 2 Normal cortical interneurons in IN-PS CDKO mice at 2 months of age. a Nissl staining of comparable sagittal sections of IN-PS CDKO mice and littermate control brains at 2 months of age shows normal gross morphology in the neocortex (NCX) and hippocampus (HP) of IN-PS CDKO mice. b Stereological quantification shows similar volume of the NCX ( $p=0.41$, Student's $t$-test) and HP ( $p=0.55)$ between IN-PS CDKO and control mice. c GAD67 immunostaining of comparable sagittal sections in the neocortex and hippocampal area CA1 of IN-PS CDKO and littermate control brains at 2 months of age. $\mathbf{d}$ Stereological quantification shows similar numbers of GAD67-immunoreactive neurons in the NCX ( $p=0.45$, Student's t-test) and HP ( $p=0.23)$ between IN-PS CDKO and control mice. Scale bar: $100 \mu \mathrm{m}$. All data are presented as the mean \pm SEM. The value in the column indicates the number of mice used in each experiment

SST, and quantified the number of PV+ or SST+ interneurons in the neocortex and hippocampus using a stereological method. We found that the number of PVimmunoreactive interneurons is significantly reduced in the neocortex of IN-PS $\mathrm{cDKO}$ mice at the age of 9 months (Control: $1.43 \pm 0.04 \times 10^{5}$, cDKO: $1.09 \pm 0.05 \times$ $10^{5}, p<0.0001$, two-way ANOVA with Bonferroni's post hoc comparisons) but not at 3 months (Fig. 4a). Similarly, the number of SST-immunoreactive interneurons is significantly reduced in the neocortex of IN-PS cDKO mice compared to controls at the age of 9 months (Control: $5.84 \pm 0.24 \times 10^{4}, \quad$ cDKO: $4.55 \pm 0.24 \times 10^{4}, \quad p=$ 0.0027, two-way ANOVA with Bonferroni's post hoc comparisons) but not at 3 months (Fig. 4b). In the hippocampus, the number of PV-immunoreactive interneurons is also significantly decreased in IN-PS cDKO mice at the age of 9 months (Control: $1.59 \pm$ $0.10 \times 10^{4}$, cDKO: $1.38 \pm 0.03 \times 10^{4}, p=0.0244$, two-way ANOVA with Bonferroni's post hoc comparisons) but not at 3 months (Fig. 4c). Similarly, the number of SSTimmunoreactive interneurons is markedly reduced in the hippocampus of IN-PS cDKO mice at the age of 9 months (Control: $1.63 \pm 0.06 \times 10^{4}$, cDKO: $1.19 \pm 0.04 \times$ $10^{4}, p<0.0001$, two-way ANOVA with Bonferroni's post hoc comparisons) but not at the age of 3 months (Fig. $4 \mathrm{~d})$. Thus, age-dependent loss of PV+ and SST+ cortical interneurons are more pronounced in IN-PS cDKO mice.

We also examined whether levels of dendritic and synaptic markers are altered in the cerebral cortex of IN-PS 


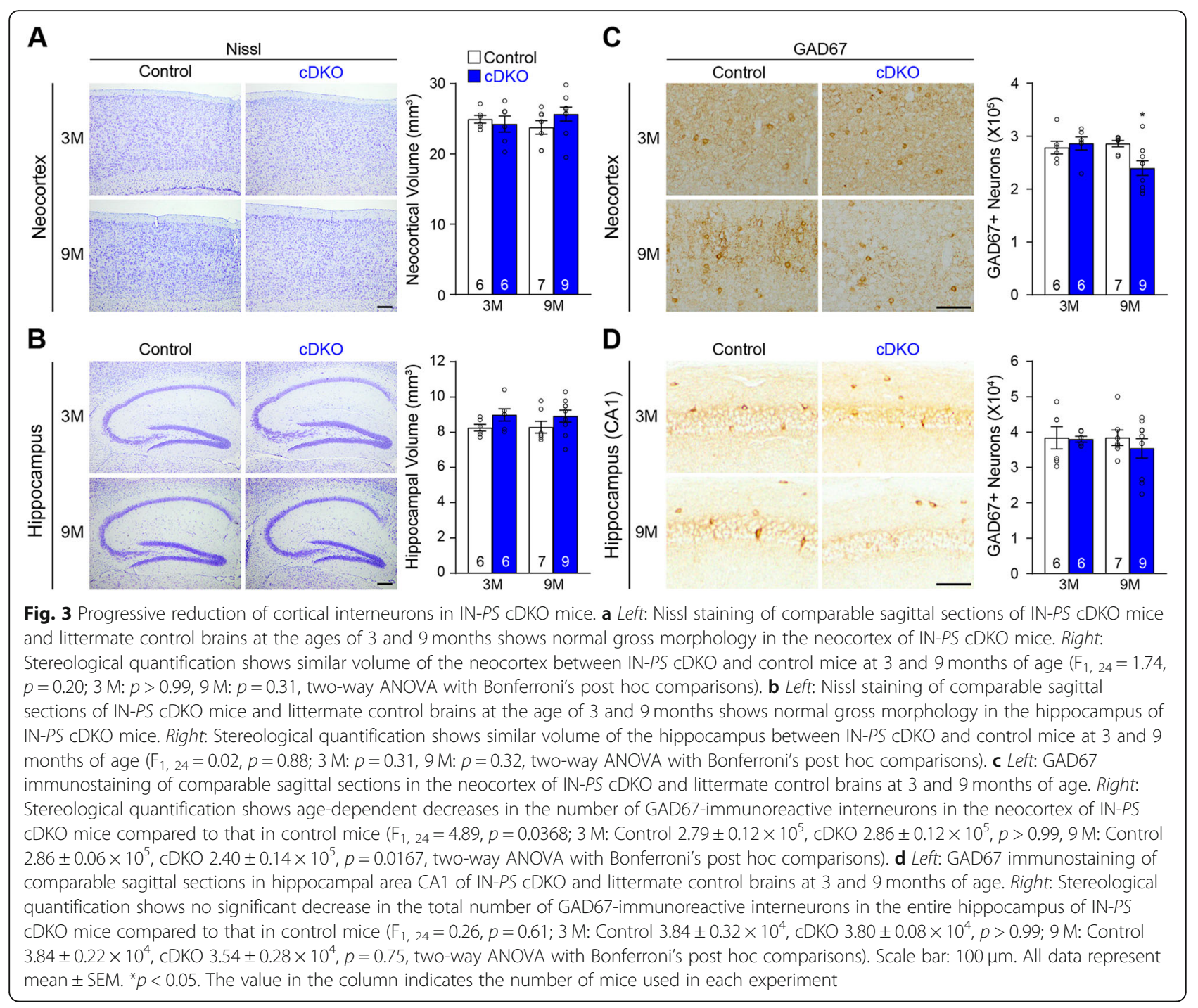

cDKO mice at 9 months of age. Western analysis of dendritic marker MAP2, and synaptic markers, synaptophysin (SYP), synaptosomal nerve-associated protein 25 (SNAP25) and postsynaptic density protein 95 (PSD95) found no significant difference in their levels in the neocortex and hippocampus between IN-PS cDKO and control mice (Fig. 5a, b).

\section{Increases of apoptotic interneurons in the cerebral cortex of IN-PS cDKO mice}

The age-dependent loss of cortical interneurons in IN$P S$ cDKO mice prompted us to examine whether apoptosis is increased. We performed immunostaining using an antibody specific for the active form of caspase-3, a marker for apoptotic cells, in the brain of IN-PS cDKO mice and littermate controls at the ages of 3 and 9 months. Stereological quantification showed that the number of active caspase-3-immunopositive cells is significantly increased in the neocortex of IN-PS cDKO mice at the ages of 3 months (Control: 200.0 \pm 27.6 ; cDKO: $415.0 \pm 83.2, p=0.0393$, two-way ANOVA with Bonferroni's post hoc multiple comparisons) and 9 months (Control: 342.9 \pm 36.4 ; cDKO: 606.7 $\pm 58.5, p=$ 0.0036; Fig. 6a, b). Furthermore, the number of active casepase-3-immunopositive apoptotic cells is also significantly increased in the hippocampus of IN-PS CDKO mice at 9 months of age (Control: $94.3 \pm 12.1$; cDKO: $376.7 \pm 68.0, p=0.0006$, two-way ANOVA with Bonferroni's post hoc multiple comparisons; Fig. 6a, b).

We also performed the TUNEL assay, and found similar increases of TUNEL+ cells in the neocortex of IN-PS cDKO at the age of 9 months (Control: $235.7 \pm 54.6$, cDKO: $730.0 \pm 130.8, p=0.0008$, two-way ANOVA with Bonferroni's post hoc multiple comparisons; Fig. 6c, d). The number of TUNEL+ cells is also significantly increased in the hippocampus of IN-PS CDKO mice at 3 


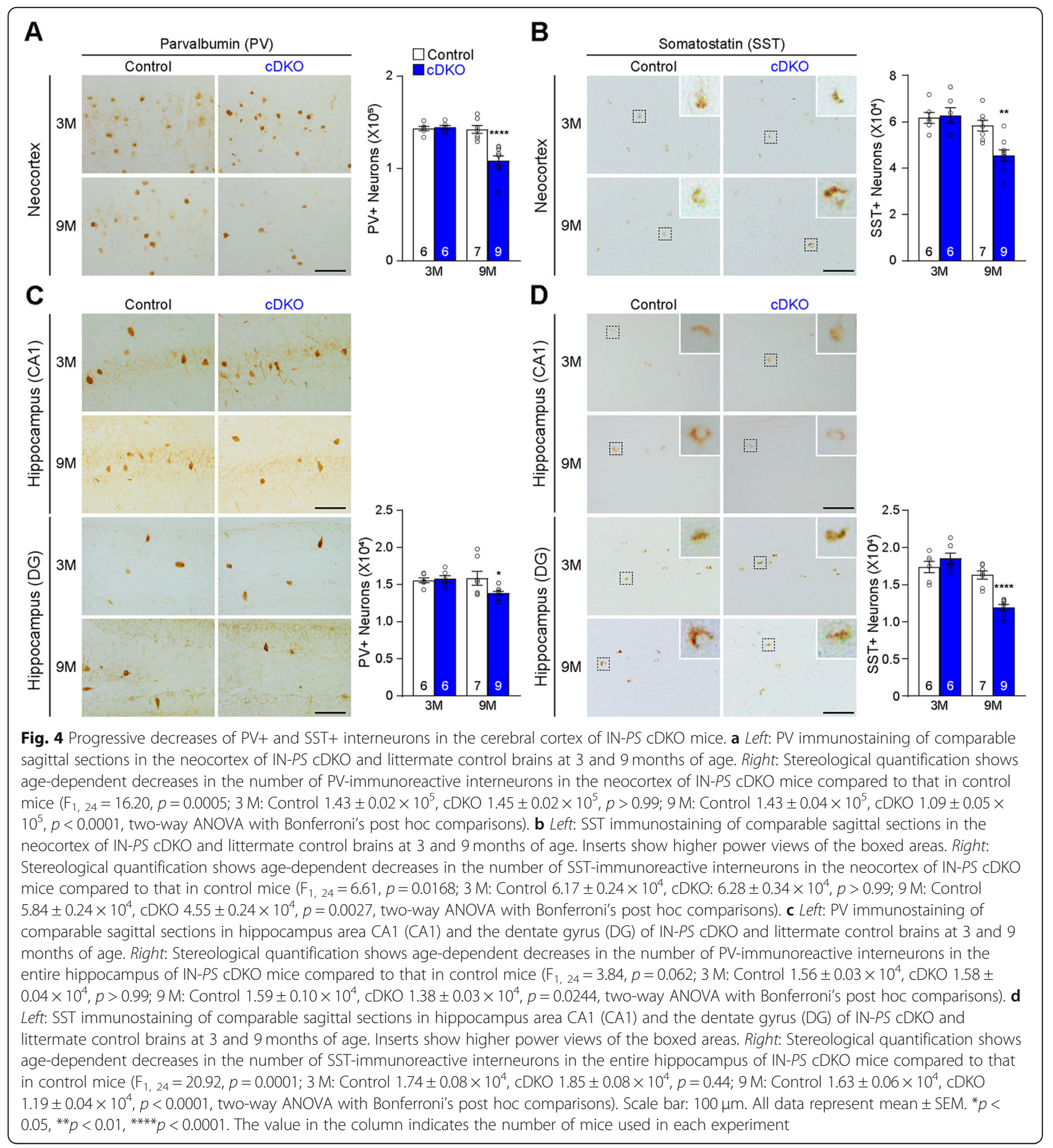

months of age (Control: $115.0 \pm 23.8$; cDKO: $320.0 \pm$ 29.7; $p=0.0014$, two-way ANOVA with Bonferroni's post hoc multiple comparisons) and at 9 months of age (Control: $137.1 \pm 23.5$, cDKO: $396.7 \pm 43.0, p<0.0001$; Fig. 6c, d).

To determine the identity of the cells undergoing apoptosis in the neocortex and hippocampus of IN-PS
cDKO mice, we performed co-immunohistological analysis using antibodies specific for active caspase-3 and CaMKII $\alpha$ for excitatory neurons or GAD67 for inhibitory interneurons. We found dramatic increases of apoptotic interneurons (active caspase-3+/GAD67+) in the neocortex and hippocampus of IN-PS cDKO mice at 9 months of age, relative to controls (Fig. 7a-e). The 

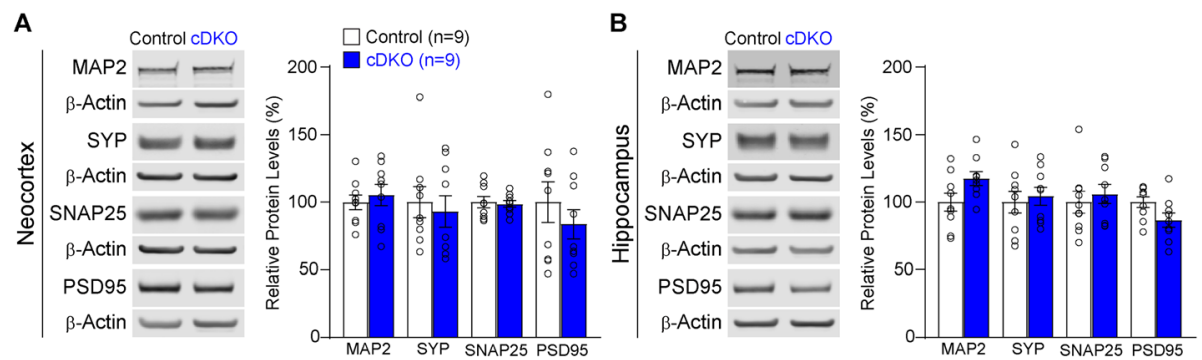

Fig. 5 Normal levels of dendritic and synaptic makers in the cortex of IN-PS CDKO mice. a Left: Western blotting of neocortical lysates of IN-PS CDKO and controls at the age of 9 months. Right: Quantification analysis shows normal levels of dendritic and synaptic markers in the neocortex of IN-PS CDKO mice relative to controls (MAP2: $p=0.59$, SYP: $p=0.68$, SNAP25: $p=0.80$, PSD95: $p=0.39$, Student's $t$-test). All values are normalized to $\beta$-Actin. $\mathbf{b}$ Left: Western blotting of hippocampal lysates of IN-PS CDKO and controls at the age of 9 months. Right: Quantification analysis shows normal levels of dendritic and synaptic markers in the hippocampus of IN-PS CDKO mice relative to controls (MAP2: $p=0.05$, SYP: $p=0.68$, SNAP25: $p=0.58$, PSD95: $p=0.07$, Student's $t$-test). All values are normalized to $\beta$-Actin. All data represent mean \pm SEM

number of non-interneuron apoptotic cells (active caspase-3+/GAD67-) in the neocortex and hippocampus is similar between control and IN-PS cDKO brains (Fig. $7 \mathrm{e})$. Furthermore, the number of apoptotic excitatory neurons (active caspase-3+/CaMKII $\alpha+$ ) in the neocortex and hippocampus is similar between IN-PS cDKO and control brains, whereas the number of apoptotic nonexcitatory neurons (active caspase-3+/CaMKII $\alpha$-) is much higher in the neocortex and hippocampus of IN$P S$ cDKO brains (Fig. 7f-j). These results together demonstrate that the increased apoptotic cells in IN-PS cDKO brains are interneurons rather than excitatory neurons.

\section{Progressive gliosis in the cerebral cortex of IN-PS CDKO mice}

Since gliosis often accompanies ongoing neurodegeneration $[11,13,14,17,41,42]$, we further evaluated whether progressive gliosis is present in the cerebral cortex of IN-PS cDKO mice. We first performed immunohistochemical analysis of GFAP, a marker of reactive astrocytes, in IN-PS CDKO and control brains at the ages of 3 and 9 months (Fig. 8a, b). Stereological quantification of GFAP immunoreactivity showed significant increases in the neocortex (Control: $2.07 \pm 0.22 \%$, cDKO: $5.93 \pm 1.39 \%, p=0.0399$, two-way ANOVA with Bonferroni's post hoc multiple comparisons; Fig. 8a) and the hippocampus (Control: $6.57 \pm 0.69 \%$, cDKO: $20.81 \pm$ $4.46 \%, p=0.0214$; Fig. $8 \mathrm{~b}$ ) of IN-PS cDKO mice at the age of 9 months. We also performed Western analysis using protein lysates from the dissected neocortex and hippocampus of IN-PS CDKO and controls at the ages of 3 and 9 months. Consistent with immunohistochemical results, we found significant increases of GFAP levels in the neocortex $(p=0.0341$, two-way ANOVA with Bonferroni's post hoc multiple comparisons; Fig. 8c) and the hippocampus ( $p=0.0108$; Fig. $8 \mathrm{~d})$ of IN-PS cDKO mice at 9 months of age.

We further evaluated microgliosis by performing immunohistochemical analysis using the microglial marker, Iba1, and saw increased Iba1 immunoreactivity in IN-PS cDKO brains at the age of 9 months. Stereological quantification showed significant increases of Iba1+ cells (Iba1+ cell number/tissue area) in the neocortex (Control: $86.17 \pm 2.90$ cells $/ \mathrm{mm}^{2}$, cDKO: $152.40 \pm 4.34$ cells/ $\mathrm{mm}^{2}, p<0.0001$, Student's $t$-test; Fig. 9a) and the hippocampus (Control: $73.70 \pm 4.64$ cells $/ \mathrm{mm}^{2}$, cDKO: $139.00 \pm 9.97$ cells $/ \mathrm{mm}^{2}, p<0.0001$, Student's $t$-test; Fig. 9b) of IN-PS cDKO mice compared to littermate controls. These data demonstrate that age-dependent loss of cortical interneurons in IN-PS cDKO brains is accompanied with astrogliosis and microgliosis.

\section{Discussion}

More than 380 mutations have been reported in the PSEN1 (320) and PSEN2 (61) genes (https://www.alzforum.org/mutations), highlighting the importance of PS in AD pathogenesis. Previous genetic studies demonstrated that selective inactivation of PS in excitatory neurons of the cerebral cortex results in age-dependent, progressive neurodegeneration including increases of apoptosis and gliosis [11-13, 16]. Subsequent studies further showed that partial reduction of PS expression in excitatory neurons of the mouse cerebral cortex or in neurons of the Drosophila brain also causes agedependent neurodegeneration and increases of apoptosis $[17,43]$. In this study, we continue this reductionist approach to dissect the role of PS in inhibitory interneurons of the cerebral cortex through the generation and analysis of IN-PS CDKO mice, in which PS expression is selectively inactivated in inhibitory interneurons using GAD2-IRES-Cre, which was shown previously to drive 

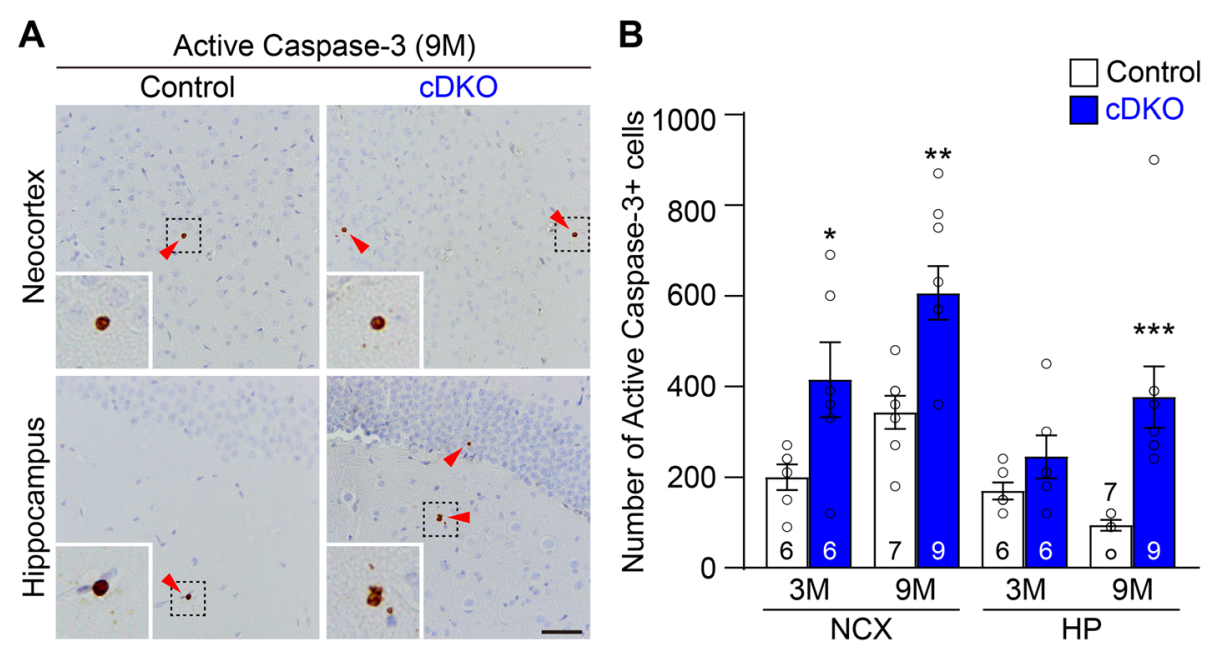

$\mathbf{C}$

TUNEL (9M)
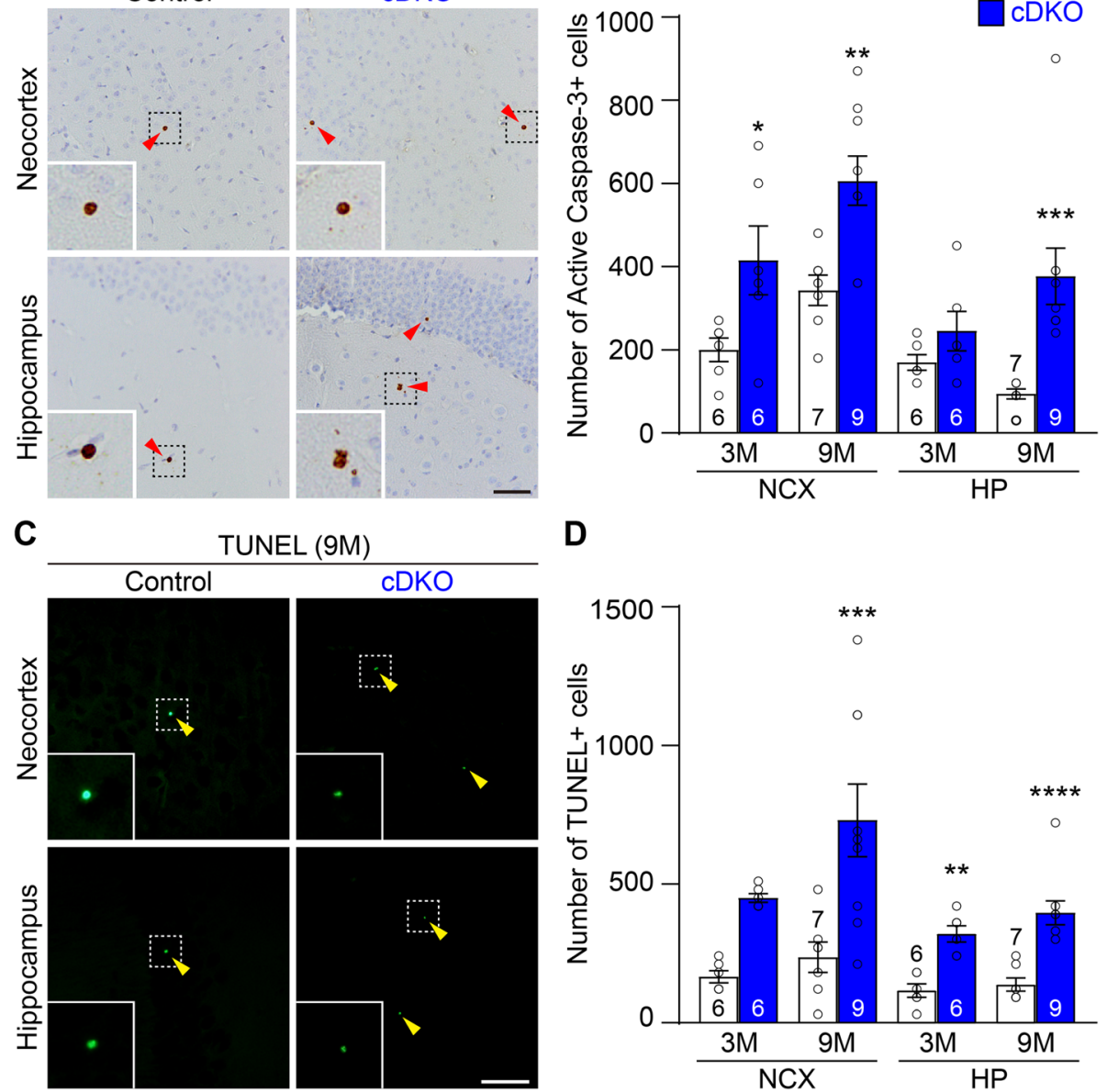

D

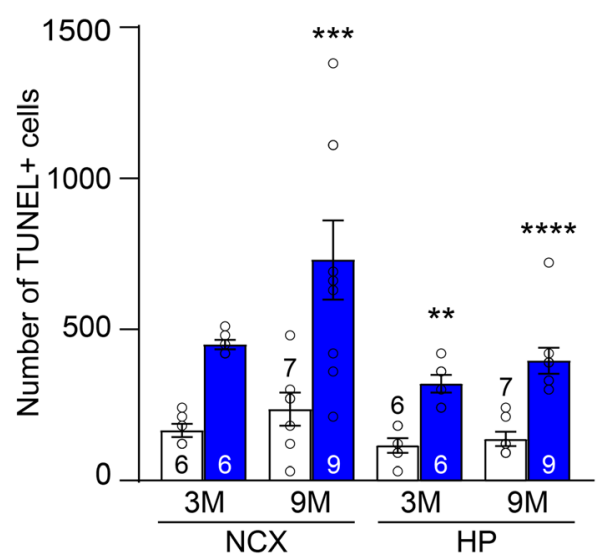

Fig. 6 Increases of apoptotic cells in the cerebral cortex of IN-PS CDKO mice. a Representative images of active caspase-3-immunoreactive cells in the neocortex (NCX) and hippocampus (HP) of control and IN-PS CDKO mice at the age of 9 months. Active caspase-3-positive cells are shown in brown with red arrowheads. Inserts show higher power views of the boxed areas. The sections were counterstained with hematoxylin. Compared to controls, there are more cells positive of active caspase-3 in the NCX and HP of IN-PS CDKO mice. $\mathbf{b}$ Stereological quantification shows significant age-dependent increases in the number of active caspase-3-immunoreactive cells in the NCX $\left(F_{1}, 24=0.18, p=0.67 ; 3 \mathrm{M}: p=0.0393,9\right.$ $\mathrm{M}: p=0.0036$, two-way ANOVA with Bonferroni's post hoc comparisons) and $\mathrm{HP}\left(\mathrm{F}_{1,24}=4.22, p=0.05 ; 3 \mathrm{M}: p=0.67,9 \mathrm{M}: p=0.0006\right)$ of IN-PS CDKO mice compared to controls. $\mathbf{c}$ Representative images of TUNEL staining in the NCX and HP of littermate control and IN-PS CDKO mice at the age of 9 months. TUNEL+ cells are shown in green with yellow arrowheads. Inserts show higher power views of the boxed areas. More TUNEL+ cells are present in the NCX and HP of IN-PS CDKO mice compared to controls. $\mathbf{d}$ Stereological quantification shows significant agedependent increases in the number of TUNEL+ cells in the NCX $\left(F_{1,24}=1.30, p=0.27 ; 3 \mathrm{M}: p=0.10,9 \mathrm{M}: p=0.0008\right.$, two-way ANOVA with Bonferroni's post hoc comparisons) and HP ( $\left.F_{1,24}=0.61, p=0.44 ; 3 \mathrm{M}: p=0.0014,9 \mathrm{M}: p<0.0001\right)$ of IN-PS cDKO mice compared to controls. Scale bar: $100 \mu \mathrm{m}$. All data represent mean \pm SEM. ${ }^{*} p<0.05,{ }^{* *} p<0.01,{ }^{* *} p<0.001,{ }^{* * *} p<0.0001$. The value in the column indicates the number of mice used in each experiment

Cre-mediated recombination in $>90 \%$ cortical interneurons [34].

Western analysis confirmed the reduction of PS1 in the neocortex $(\sim 15 \%)$ and hippocampus $(\sim 11 \%)$ of INPS cDKO brains (Fig. 1), consistent with the percentages of interneurons in the neocortex (15-20\%) and hippocampus (10-15\%), respectively [44]. The remaining PS1 detected on the Western blot is due to normal levels of PS1 expressed in excitatory neurons and glial populations, which lack Cre expression. Thus, the IN-PS cDKO brain is a mosaic, composed of interneurons lacking PS and excitatory neurons and glia expressing normal levels of PS1. The lack of PS in interneurons results in complete loss of $\gamma$-secretase activity, leading to dramatic accumulation of the physiological substrates APP CTFs in IN-PS CDKO brains (Fig. 1).

While IN-PS cDKO mice at 2 months of age exhibit normal spontaneous activities in the open field (Fig. 1), they begin to die at this age and their median lifespan is $\sim 3$ months. The exact cause of the early lethality in IN- 


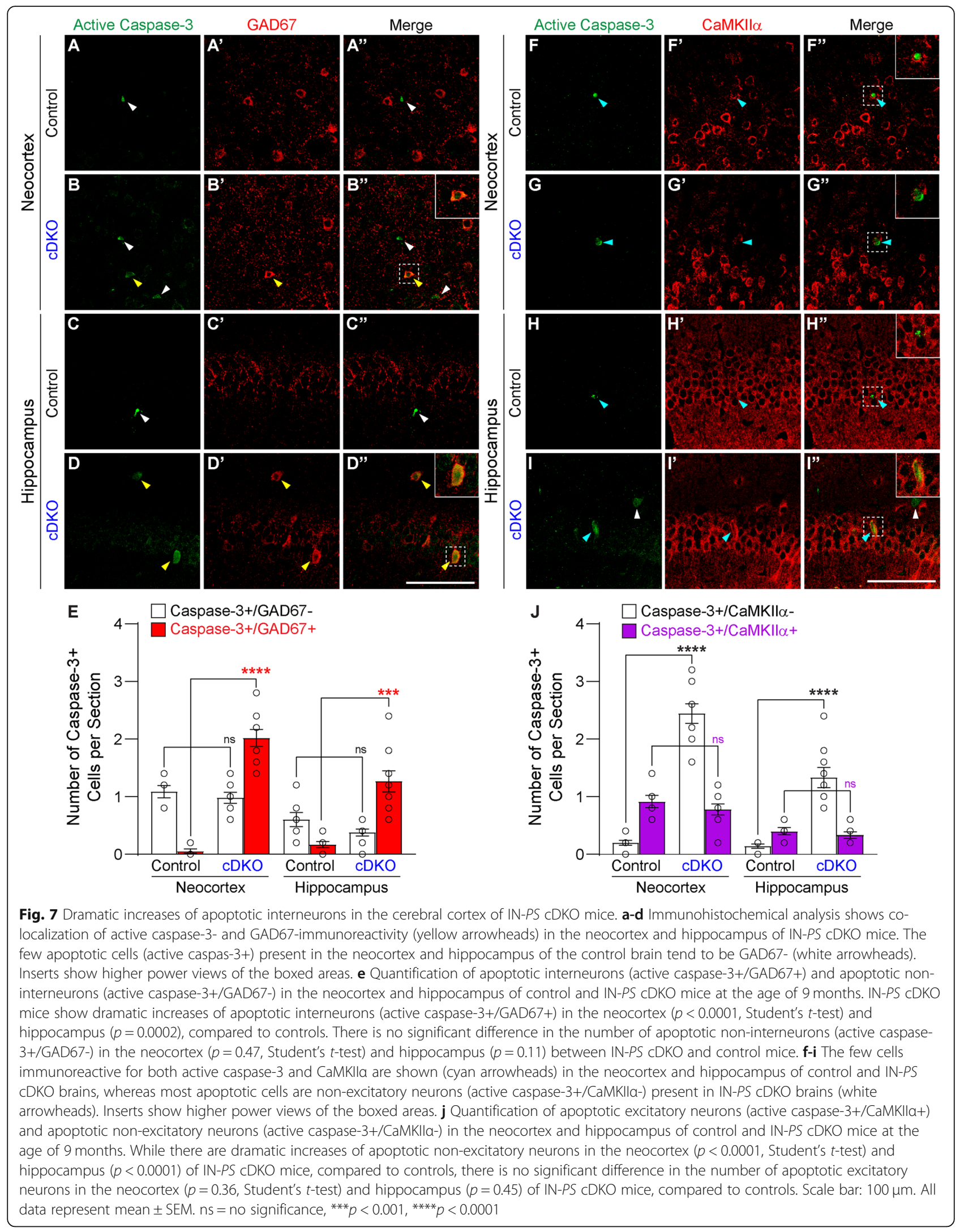




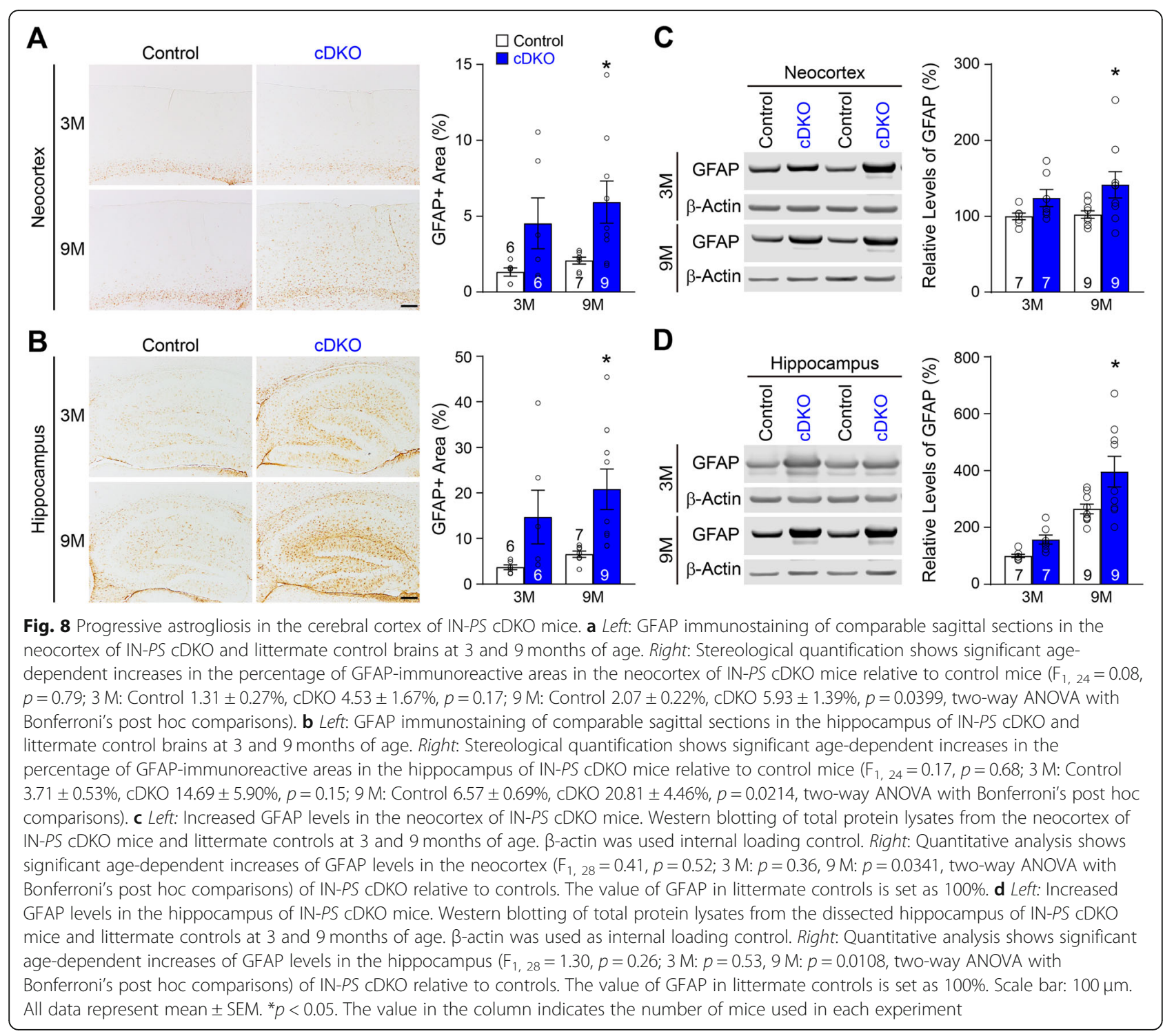

$P S$ cDKO mice is unclear. Given that interneurons in the brainstem and spinal cord are thought to control vital functions like breathing and swallowing, etc. [4547], we speculate that interneuron dysfunction and degeneration caused by PS inactivation may underlie early lethality in IN-PS cDKO mice. Indeed, it was previously demonstrated that selective inactivation of PS in excitatory neurons results in synaptic dysfunction, such as impairments in neurotransmitter release, short-term and long-term synaptic plasticity, and intracellular $\mathrm{Ca}^{2+}$ homeostasis, followed by progressive, striking neurodegeneration [13, 15-18, 48, 49]. It therefore would be of great interest to perform similar electrophysiological analysis to determine the consequences of selective PS inactivation in interneurons on inhibitory and excitatory synaptic responses in the hippocampal local network and to investigate whether loss of PS in interneurons similarly disrupts intracellular $\mathrm{Ca}^{2+}$ homeostasis in a cell-autonomous manner.

Cre expression in IN-PS cDKO brains is under the control of the endogenous GAD2 promoter, beginning approximately at embryonic day 10.5 [37]. Our quantitative histological analysis showed normal morphology and number of inhibitory interneurons in the cerebral cortex of IN-PS CDKO mice at 2 months of age, indicating normal generation and maturation of cortical inhibitory neurons in IN-PS cDKO mice (Fig. 2). However, as IN-PS cDKO mice age, they develop age-dependent loss of GAD67+ cortical interneurons as well as the PV+ and SST + subgroups of interneurons in the cerebral cortex (Figs. 3, 4). The significant reduction of cortical interneurons in IN-PS cDKO brains at 9 months is preceded by increases of apoptosis at 3 months (Fig. 6). Furthermore, the increased apoptotic cells in the cerebral cortex 

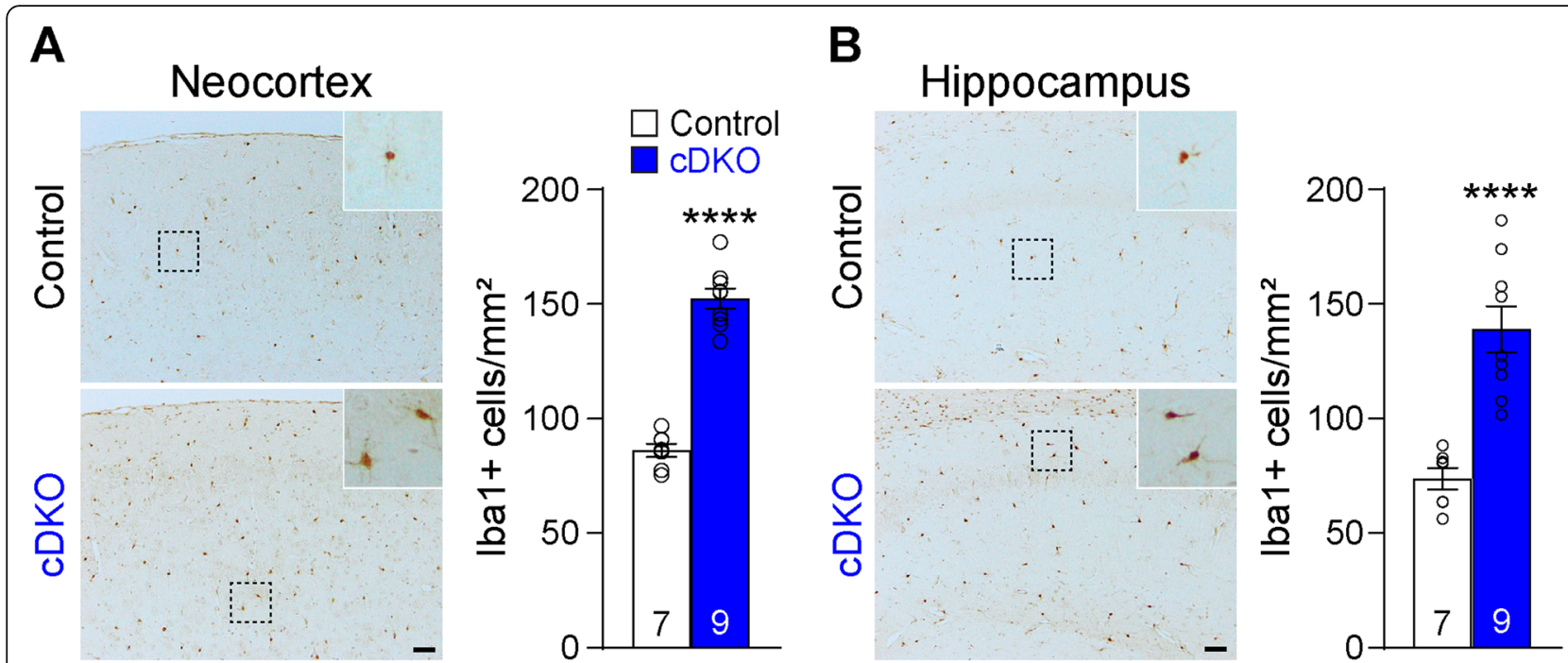

Fig. 9 Microgliosis in the cerebral cortex of IN-PS CDKO mice. a Left: Iba1 immunostaining of comparable sagittal sections in the neocortex of INPS CDKO and littermate control brains at 9 months of age. Inserts show higher power views of the boxed areas. Right: Stereological quantification shows significant age-dependent increases in the number of Iba1-immunoreactive cells in the neocortex of IN-PS CDKO mice relative to control mice (Control: $86.17 \pm 2.90$ cells $/ \mathrm{mm}^{2}$, cDKO: $152.40 \pm 4.34$ cells $/ \mathrm{mm}^{2}, p<0.0001$, Student's $t$-test). b Left: Iba1 immunostaining of comparable sagittal sections in the hippocampus of IN-PS CDKO and littermate control brains at 9 months of age. Inserts show higher power views of the boxed areas. Right: Stereological quantification shows significant age-dependent increases in the number of Iba1-immunoreactive cells in the neocortex of IN-PS CDKO mice relative to control mice (Control: $73.70 \pm 4.64$ cells $/ \mathrm{mm}^{2}$, cDKO: $139.00 \pm 9.97 \mathrm{cells} / \mathrm{mm}^{2}, p<0.0001$, Student's $t$ test). Scale bar: $100 \mu \mathrm{m}$. All data represent mean \pm SEM. ${ }^{* * *} p<0.0001$. The value in the column indicates the number of mice used in each experiment

of IN-PS cDKO mice are interneurons instead of excitatory neurons (Fig. 7). Thus, the significant reduction of cortical interneurons in IN-PS cDKO mice at 9 months is likely due to cumulative loss of apoptotic interneurons between 3 and 9 months of age. However, cortical volume (Fig. 3) and synaptic and dendritic markers (Fig. 5) are not significantly reduced in IN-PS cDKO mice at 9 months, likely due to the small percentage of interneurons in the cerebral cortex (10-20\%), in contrast to $35 \%$ reduction of cortical volume in EX-PS cDKO mice at 9 months of age because of $>80 \%$ excitatory neurons in the cerebral cortex $[13,16]$. Furthermore, despite the small reduction of cortical interneurons (e.g. 22-24\% $\mathrm{PV}+$ and SST+ subgroups) in IN-PS $\mathrm{cDKO}$ mice at 9 months and the small percentage of interneurons in the cerebral cortex (10-20\%), loss of cortical interneurons, which represents $<4 \%$ of all neurons, is accompanied with astrogliosis and microgliosis (Figs. 8, 9), similarly as previously reported in mouse models that exhibit agedependent neuronal loss $[11,13,16,17,50,51]$.

Neuropathological changes in AD appear to occur first in the entorhinal cortex and hippocampus, and then extend to the rest of the neocortex [52]. Although most studies focused on the degeneration of excitatory neurons in the entorhinal cortex and hippocampus, vulnerability of interneurons has been reported in postmortem AD brains [25-30]. Specifically, loss of PV- and SSTexpressing interneurons has been reported in the cerebral cortex of postmortem AD brains [26, 27, 31, 53-57]. Thus, age-dependent loss of PV- and SSTexpressing interneurons observed in the neocortex and hippocampus of IN-PS cDKO mice (Fig. 4) may be relevant to similar loss of cortical interneuron in postmortem AD brains.

The molecular mechanism by which PS supports the survival of excitatory neurons and interneurons in the cerebral cortex is unknown. Since Notch receptors and APP family members are physiological substrates of PS, we previously conducted genetic studies to determine whether inactivation of Notch1/2 or APP/APLP1/APLP2 similarly causes age-dependent cortical neurodegeneration using the same Camk2a-Cre transgenic line that was used to inactivate PS $[10,13]$. Surprisingly, no neuronal loss was observed in the cerebral cortex of Notch1/ $2 \mathrm{cDKO}$ mice [58] and APP/APLP1/APLP2 conditional triple knockout mice [59], demonstrating that PS mediated cortical neuronal survival is not regulated through the Notch or APP family. Given the fact at any given time only $0.1-0.2 \%$ of excitatory or inhibitory cortical neurons lacking PS undergo apoptosis, making it impossible to perform biochemical analysis to gain insight into the molecular mechanism, we have therefore developed Drosophila models [43] and are now looking for genes that modulate age-dependent neurodegeneration caused by partial loss of Psn, the Drosophila homolog of Presenilin. 


\section{Conclusions}

Our current study shows that selective inactivation of Presenilin in interneurons results in age-dependent loss of cortical interneurons and increases of apoptotic interneurons as well as astrogliosis and microgliosis in the cerebral cortex. These findings, together with earlier reports, demonstrate a universal, essential role of PS in the survival of both excitatory and inhibitory neurons during aging.

\section{Supplementary Information}

The online version contains supplementary material available at https://doi. org/10.1186/s13024-020-00419-y.

\section{Additional file 1.}

\section{Abbreviations}

AD: Alzheimer's disease; APP: Amyloid precursor protein; CaMKIla: Calcium/ calmodulin-dependent protein kinase type II subunit alpha; Cre: Cre recombinase; CTF: C-terminal fragment; EX-PS CDKO: Excitatory neuronspecific PS conditional double knockout; FAD: Familial Alzheimer's disease; GABA: $\gamma$-aminobutyric acid; GAD: Glutamate decarboxylase; GFAP: Glial fibrillary acidic protein; HP: Hippocampus; Iba1: Ionized calcium-binding adapter molecule 1; IN-PS CDKO: Inhibitory neuron-specific PS conditional double knockout; IRES: Internal ribosome entry site; Kl: Knockin; MAP 2: Microtubule-associated protein 2; NCX: Neocortex; PGK: Phosphoglycerate kinase; PS: Presenilin; PSD95: Postsynaptic density protein 95; PV: Parvalbumin; SNAP25: Synaptosomal-associated protein, 25 kDa; SST: Somatostatin; SYP: Synaptophysin; TUNEL: Terminal deoxynucleotidyl transferase dUTP nick end labeling; 5HT3aR: 5hydroxytryptamin (serotonin) receptor $3 \mathrm{~A}$

\section{Acknowledgements}

We thank Morgan Fraser for technical assistance and the Shen lab members for discussion.

\section{Authors' contributions}

J.S. conceived and directed the projects, J.K. generated the IN-PS CDKO mice and performed experiments, J.S. and J.K. wrote the paper. All authors read and approved the final manuscript.

\section{Funding}

This work was supported by a grant from the NINDS (R01NS041783 to J.S.)

\section{Availability of data and materials}

The datasets generated and analyzed during the current study are available from the corresponding author upon request.

\section{Ethics approval and consent to participate}

Not applicable.

\section{Consent for publication}

Not applicable.

\section{Competing interests}

J.S. is a member of the Board of Directors and has a financial interest in iNeuro Therapeutics, and J.S. also has a financial interest in Apres

Therapeutics. Both companies develop therapies for Alzheimer's disease. J.S.'s interests were reviewed and are managed by BWH and Partners HealthCare in accordance with their conflict of interest policies.
Received: 30 June 2020 Accepted: 1 December 2020

Published online: 10 December 2020

\section{References}

1. Shen J, Kelleher RJ 3rd. The presenilin hypothesis of Alzheimer's disease: evidence for a loss-of-function pathogenic mechanism. Proc Natl Acad Sci U S A. 2007:104(2):403-9.

2. Lee MK, Slunt HH, Martin LJ, Thinakaran G, Kim G, Gandy SE, et al. Expression of presenilin 1 and 2 (PS1 and PS2) in human and murine tissues. J Neurosci. 1996;16(23):7513-25.

3. Kovacs DM, Fausett HJ, Page KJ, Kim TW, Moir RD, Merriam DE, et al. Alzheimer-associated presenilins 1 and 2: neuronal expression in brain and localization to intracellular membranes in mammalian cells. Nat Med. 1996; 2(2):224-9.

4. Mathews PM, Cataldo AM, Kao BH, Rudnicki AG, Qin X, Yang JL, et al. Brain expression of presenilins in sporadic and early-onset, familial Alzheimer's disease. Mol Med. 2000;6(10):878-91.

5. Li YM, Xu M, Lai MT, Huang Q, Castro JL, DiMuzio-Mower J, et al. Photoactivated gamma-secretase inhibitors directed to the active site covalently label presenilin 1. Nature. 2000:405(6787):689-94.

6. Shen J, Bronson RT, Chen DF, Xia W, Selkoe DJ, Tonegawa S. Skeletal and CNS defects in Presenilin-1-deficient mice. Cell. 1997:89(4):629-39.

7. Handler M, Yang $X$, Shen J. Presenilin-1 regulates neuronal differentiation during neurogenesis. Development. 2000;127(12):2593-606.

8. Kim WY, Shen J. Presenilins are required for maintenance of neural stem cells in the developing brain. Mol Neurodegener. 2008;3:2.

9. Xia X, Qian S, Soriano S, Wu Y, Fletcher AM, Wang XJ, et al. Loss of presenilin 1 is associated with enhanced beta-catenin signaling and skin tumorigenesis. Proc Natl Acad Sci U S A. 2001;98(19):10863-8.

10. Yu H, Saura CA, Choi SY, Sun LD, Yang X, Handler M, et al. APP processing and synaptic plasticity in presenilin-1 conditional knockout mice. Neuron. 2001;31(5):713-26.

11. Beglopoulos V, Sun X, Saura CA, Lemere CA, Kim RD, Shen J. Reduced beta-amyloid production and increased inflammatory responses in presenilin conditional knock-out mice. J Biol Chem. 2004;279(45): 46907-14.

12. Feng $R$, Wang $H$, Wang J, Shrom D, Zeng $X$, Tsien JZ. Forebrain degeneration and ventricle enlargement caused by double knockout of Alzheimer's presenilin-1 and presenilin-2. Proc Natl Acad Sci U S A. 2004; 101(21):8162-7.

13. Saura CA, Choi SY, Beglopoulos V, Malkani S, Zhang D, Shankaranarayana Rao BS, et al. Loss of presenilin function causes impairments of memory and synaptic plasticity followed by age-dependent neurodegeneration. Neuron. 2004:42(1):23-36.

14. Tabuchi K, Chen G, Sudhof TC, Shen J. Conditional forebrain inactivation of nicastrin causes progressive memory impairment and age-related neurodegeneration. J Neurosci. 2009;29(22):7290-301.

15. Zhang C, Wu B, Beglopoulos V, Wines-Samuelson M, Zhang D, Dragatsis I, et al. Presenilins are essential for regulating neurotransmitter release. Nature. 2009:460(7255):632-6.

16. Wines-Samuelson M, Schulte EC, Smith MJ, Aoki C, Liu X, Kelleher RJ 3rd, et al. Characterization of age-dependent and progressive cortical neuronal degeneration in presenilin conditional mutant mice. PLoS One. 2010;5(4): e10195.

17. Watanabe H, Iqbal M, Zheng J, Wines-Samuelson M, Shen J. Partial loss of presenilin impairs age-dependent neuronal survival in the cerebral cortex. J Neurosci. 2014;34(48):15912-22.

18. Lee SH, Lutz D, Mossalam M, Bolshakov W, Frotscher M, Shen J. Presenilins regulate synaptic plasticity and mitochondrial calcium homeostasis in the hippocampal mossy fiber pathway. Mol Neurodegener. 2017;12(1):48.

19. Lee SH, Sharma M, Sudhof TC, Shen J. Synaptic function of nicastrin in hippocampal neurons. Proc Natl Acad Sci U S A. 2014;111(24):8973-8.

20. Freund TF, Buzsaki G. Interneurons of the hippocampus. Hippocampus. 1996;6(4):347-470

21. Paulsen O, Moser El. A model of hippocampal memory encoding and retrieval: GABAergic control of synaptic plasticity. Trends Neurosci. 1998; 21(7):273-8

22. Markram H, Toledo-Rodriguez M, Wang Y, Gupta A, Silberberg G, Wu C. Interneurons of the neocortical inhibitory system. Nat Rev Neurosci. 2004 5(10):793-807. 
23. Lim L, Mi D, Llorca A, Marin O. Development and functional diversification of cortical interneurons. Neuron. 2018;100(2):294-313.

24. Tremblay R, Lee $S$, Rudy B. GABAergic interneurons in the Neocortex: from cellular properties to circuits. Neuron. 2016;91(2):260-92.

25. Saiz-Sanchez D, Ubeda-Banon I, de la Rosa-Prieto C, Argandona-Palacios L, Garcia-Munozguren S, Insausti R, et al. Somatostatin, tau, and beta-amyloid within the anterior olfactory nucleus in Alzheimer disease. Exp Neurol. 2010; 223(2):347-50

26. Solodkin A, Veldhuizen SD, Van Hoesen GW. Contingent vulnerability of entorhinal parvalbumin-containing neurons in Alzheimer's disease. $J$ Neurosci. 1996;16(10):3311-21.

27. Davies $P$, Katzman $R$, Terry RD. Reduced somatostatin-like immunoreactivity in cerebral cortex from cases of Alzheimer disease and Alzheimer senile dementa. Nature. 1980;288(5788):279-80.

28. Norris PJ, Faull RL, Emson PC. Neuronal nitric oxide synthase (nNOS) mRNA expression and NADPH-diaphorase staining in the frontal cortex, visual cortex and hippocampus of control and Alzheimer's disease brains. Brain Res Mol Brain Res. 1996;41(1-2):36-49.

29. Stefanits H, Wesseling C, Kovacs GG. Loss of Calbindin immunoreactivity in the dentate gyrus distinguishes Alzheimer's disease from other neurodegenerative dementias. Neurosci Lett. 2014;566:137-41.

30. Thorns V, Hansen L, Masliah E. nNOS expressing neurons in the entorhinal cortex and hippocampus are affected in patients with Alzheimer's disease. Exp Neurol. 1998;150(1):14-20.

31. Sanchez-Mejias E, Nunez-Diaz C, Sanchez-Varo R, Gomez-Arboledas A, Garcia-Leon JA, Fernandez-Valenzuela JJ, et al. Distinct disease-sensitive GABAergic neurons in the perirhinal cortex of Alzheimer's mice and patients. Brain Pathol. 2019;30(2):345-63.

32. Palop JJ, Mucke L. Network abnormalities and interneuron dysfunction in Alzheimer disease. Nat Rev Neurosci. 2016;17(12):777-92.

33. Villette $V$, Dutar P. GABAergic microcircuits in Alzheimer's disease models. Curr Alzheimer Res. 2017;14(1):30-9.

34. Taniguchi H, He M, Wu P, Kim S, Paik R, Sugino K, et al. A resource of Cre driver lines for genetic targeting of GABAergic neurons in cerebral cortex. Neuron. 2011;71(6):995-1013.

35. Yamaguchi $\mathrm{H}$, Shen J. Histological analysis of neurodegeneration in the mouse brain. Methods Mol Biol. 2013;1004:91-113.

36. Yu H, Kessler J, Shen J. Heterogeneous populations of ES cells in the generation of a floxed Presenilin-1 allele. Genesis. 2000;26(1):5-8.

37. Katarova Z, Sekerkova G, Prodan S, Mugnaini E, Szabo G. Domain-restricted expression of two glutamic acid decarboxylase genes in midgestation mouse embryos. J Comp Neurol. 2000;424(4):607-27.

38. Lee S, Hjerling-Leffler J, Zagha E, Fishell G, Rudy B. The largest group of superficial neocortical GABAergic interneurons expresses ionotropic serotonin receptors. J Neurosci. 2010;30(50):16796-808.

39. Xu X, Roby KD, Callaway EM. Immunochemical characterization of inhibitory mouse cortical neurons: three chemically distinct classes of inhibitory cells. J Comp Neurol. 2010;518(3):389-404.

40. Meyer HS, Schwarz D, Wimmer VC, Schmitt AC, Kerr JN, Sakmann B, et al. Inhibitory interneurons in a cortical column form hot zones of inhibition in layers 2 and 5A. Proc Natl Acad Sci U S A. 2011;108(40): 16807-12.

41. Lobsiger CS, Cleveland DW. Glial cells as intrinsic components of noncell-autonomous neurodegenerative disease. Nat Neurosci. 2007;10(11): 1355-60.

42. Heneka MT, Rodriguez JJ, Verkhratsky A. Neuroglia in neurodegeneration. Brain Res Rev. 2010;63(1-2):189-211.

43. Kang J, Shin S, Perrimon N, Shen J. An evolutionarily conserved role of Presenilin in neuronal protection in the aging Drosophila brain. Genetics. 2017;206(3):1479-93.

44. Keller D, Ero C, Markram H. Cell densities in the mouse brain: a systematic review. Front Neuroanat. 2018:12:83

45. Smith JC, Abdala AP, Borgmann A, Rybak IA, Paton JF. Brainstem respiratory networks: building blocks and microcircuits. Trends Neurosci. 2013;36(3): $152-62$

46. Angeles Fernandez-Gil M, Palacios-Bote R, Leo-Barahona M, Mora-Encinas JP. Anatomy of the brainstem: a gaze into the stem of life. Semin Ultrasound CT MR. 2010;31(3):196-219.

47. Barlow SM. Central pattern generation involved in oral and respiratory control for feeding in the term infant. Curr Opin Otolaryngol Head Neck Surg. 2009;17(3):187-93.
48. Zhang D, Zhang C, Ho A, Kirkwood A, Sudhof TC, Shen J. Inactivation of presenilins causes pre-synaptic impairment prior to post-synaptic dysfunction. J Neurochem. 2010;115(5):1215-21.

49. Wu B, Yamaguchi H, Lai FA, Shen J. Presenilins regulate calcium homeostasis and presynaptic function via ryanodine receptors in hippocampal neurons. Proc Natl Acad Sci U S A. 2013;110(37):15091-6.

50. Xia D, Watanabe H, Wu B, Lee SH, Li Y, Tsvetkov E, et al. Presenilin-1 knockin mice reveal loss-of-function mechanism for familial Alzheimer's disease. Neuron. 2015:85(5):967-81.

51. Giaime E, Tong Y, Wagner LK, Yuan Y, Huang G, Shen J. Age-dependent dopaminergic Neurodegeneration and impairment of the autophagyLysosomal pathway in LRRK-deficient mice. Neuron. 2017;96(4):796-807 e6.

52. Braak H, Braak E. Neuropathological stageing of Alzheimer-related changes. Acta Neuropathol. 1991;82(4):239-59.

53. Arai $\mathrm{H}$, Emson PC, Mountjoy CQ, Carassco LH, Heizmann CW. Loss of parvalbumin-immunoreactive neurones from cortex in Alzheimer-type dementia. Brain Res. 1987;418(1):164-9.

54. Satoh J, Tabira T, Sano M, Nakayama H, Tateishi J. Parvalbuminimmunoreactive neurons in the human central nervous system are decreased in Alzheimer's disease. Acta Neuropathol. 1991;81(4):388-95.

55. Brady DR, Mufson EJ. Parvalbumin-immunoreactive neurons in the hippocampal formation of Alzheimer's diseased brain. Neuroscience. 1997; 80(4):1113-25

56. Mikkonen M, Alafuzoff I, Tapiola T, Soininen H, Miettinen R. Subfield- and layer-specific changes in parvalbumin, calretinin and calbindin-D28K immunoreactivity in the entorhinal cortex in Alzheimer's disease. Neuroscience. 1999;92(2):515-32.

57. Kumar U. Expression of somatostatin receptor subtypes (SSTR1-5) in Alzheimer's disease brain: an immunohistochemical analysis. Neuroscience. 2005;134(2):525-38.

58. Zheng J, Watanabe H, Wines-Samuelson M, Zhao H, Gridley T, Kopan R, et al. Conditional deletion of Notch1 and Notch2 genes in excitatory neurons of postnatal forebrain does not cause neurodegeneration or reduction of notch mRNAs and proteins. J Biol Chem. 2012;287(24): 20356-68.

59. Lee SH, Kang J, Ho A, Watanabe H, Bolshakov VY, Shen J. APP family regulates neuronal excitability and synaptic plasticity but not neuronal survival. Neuron. 2020;108:676-90.

\section{Publisher's Note}

Springer Nature remains neutral with regard to jurisdictional claims in published maps and institutional affiliations.

Ready to submit your research? Choose BMC and benefit from:

- fast, convenient online submission

- thorough peer review by experienced researchers in your field

- rapid publication on acceptance

- support for research data, including large and complex data types

- gold Open Access which fosters wider collaboration and increased citations

- maximum visibility for your research: over $100 \mathrm{M}$ website views per year

At $\mathrm{BMC}$, research is always in progress.

Learn more biomedcentral.com/submission 